\title{
Gender-based empirical research on the needs for organizational culture from the green-hand employees in automotive company
}

\author{
He Ying, Luo Jinlian, Liu Shi, Sun Xin, Sun Junchi \\ Department of Tongji University of Siping Road 1239, Shanghai, China
}

\begin{abstract}
The organizational culture is the key effect on employees' career development. This paper studies the needs for organizational culture from the green-hand employees in automotive industry, who are the graduates in School of Automotive Studies, with the empirical method. The result shows that, there are differences between green-hand employees of different genders in the needs for organizational culture of automotive enterprises. The further gender-based research on the difference in needs for organizational culture from the green-hand employees contributes to meeting their needs better for automotive enterprises by optimizing the internal organizational culture, and is of positive significance for the automotive graduates to get better career development.

Keywords: automotive industry; organizational culture; greenhand employee; gender perspective;
\end{abstract}

\section{Backgrounds}

Previous Qualitative research finds that organizational culture is a key factor to affect the career development, and automotive employees of different gender are significant the need for organizational culture. The main purpose of this paper is to test the conclusions of organizational culture needs from the perspective of gender-based auto companies' employees. Since previous studies focus mostly on the young employees of the auto companies, after a trial research, it is found that the thinking and need for graduates major in automotive studies with the automotive industry practice in the auto companies match the ones for new employees. Their need for organizational culture can be seen as the need for auto companies of new employees to test some of the conclusions of our previous studies. Thus, the study contributes to the auto companies to optimize the internal organizational culture, and fit new employees on organizational culture, also for new employees getting a good career development of positive significance.

\section{Review of literature}

\section{A. Organizational culture}

In many studies, Denison's model of organizational cultures one of the commonly used tools in the western organizational culture construction. ${ }^{[1]-[5]}$ The researcher from Swiss Institute for Management Development (IMD), Professor Daniel Denison believes that organizational culture as a deep structure of the organization, rooted in members of the organization with some values, beliefs and hypothesis. In order to construct the structural model of organizational culture, Dennison studied the performance data of the 34 companies from the early 1980s, and over time, this database already contains more than 1500 companies in North America, Australia, Asia, South Americas well as Europe and other places. The global results of the study show that: adaptability, mission, involvement, consistency these four cultural traits significantly associate with organizational effectiveness. Involvement and consistency emphasized the company's internal systems, organizational structure, and process integration. In order to describe the characteristics of the organizational culture of internal integration, each trait has three dimensions to measure, for example, involvements in the three dimensions of F1(authorization), F2(team orientation), F3(ability development); consistency is divided into F4(core values), F5(cooperation), F6(coordination and integration) these three dimensions. To achieve the purpose of this study each dimension is measured.

\section{B. Gender segregation}

Occupational gender segregation means that in the labour market, both males and female employees are assigned, concentrated to a different career as a different nature. (Gross, 1968; Birkelund, 1992; Watts, 1998). ${ }^{\text {[61 }}$ That is to say, the gender distribution of the occupation practitioners presented the state of imbalance, and entry and promotion channels monopolized by the majority of the population of a particular gender. ${ }^{[71}$ In order to study the gender segregation of the industry, many scholars are on its mathematical analysis, statistics, as well as management of different angles. In recent years, with the development of China's automobile industry, the proportion of female employees in the auto companies gradually increase, not only males but also female employees in the males-dominated sectors of the career development attract more and more attention. Therefore, the study helps to understand the new employees of different gender who have difference in organizational culture needs and to fit their needs for organizational support, to build organizational identity for the new employees, and thus to enable them to make better career development of great significance. ${ }^{\text {[81 - [111] }}$

\section{Research methods}

A. Research hypothesis

There are differences between green-hand automotive employees both of different genders and same gender in the needs for organizational culture. The previous qualitative research has drawn some conclusions of the exploratory, and 
this study regarding these conclusions makes the following research hypothesis and research.

Fundamental hypothesis H0: The green-hand automotive employees have different needs for organizational culture; based on gender perspective, the difference between different genders is more significant than the one within the same gender

Sub-hypothesis H10: For the difference of needs for each dimension of organizational culture between green-hand automotive employees of different genders, the gender difference is most significant in 'team orientation' and 'cooperation'.

Sub-hypothesis H20: For the difference of needs for each dimension of organizational culture within green-hand automotive employees of the same gender, females have the most significant individual difference in 'authorization' and ‘cooperation', and males in 'cooperation'.

\section{B. Questionnaire organization and trial research}

The questionnaire bases on the original questionnaire, which studies the employees in the needs for the six internal dimensions of organizational culture of automotive enterprises in the previous qualitative research, in order to accommodate to the actual situation of graduates (green-hand employees of automotive enterprises) and make further modification in certain items. For this, the study randomly selects 10 graduates of automotive engineering college and makes a pre-trial research to ask for advice and be scored. Through the pre-trial research, the formal questionnaire is revised to be composed of 17 items derived from the six internal dimensions of organizational culture and used 10-point measure system (the higher the score, the stronger the need).

\section{Research Subject}

In the formal research, study selects 180 graduates of automotive engineering college in a university as testers, which have internship experience in the automotive enterprises and the similar organizational culture needs of green-hand employees found in the pre-research. And the testers are distributed in different automotive professional directions. Besides to accord with the actual situation of green-hand employees as far as possible, testers' distribution is balanced in the ratio of gender, professional direction and other factors.

Gathered up a great amount of data from face-to-face questionnaires, e-mail and telephone interviews. Results are 180 questionnaires and 165 recalled, the response rate is $91.7 \%$ and 152 questionnaires are effective, effective rate is $92.1 \%$.

\section{Data analysis method}

This study adopts the standardized normal distribution theory to infer the probability of difference and the method of Z-test to infer the significance of difference.

\section{Data analysis and calculating results}

Through statistical analysis of data, the results show that, the overall degree of green-hand automotive employees in the needs for organizational culture is high $(\bar{X}=6.32)$, and the variance of $S=2.99$, data distribution is close to the normal distribution. This shows that the green-hand automotive employees in the needs for organizational culture have high degree of need. (Fig. 1)

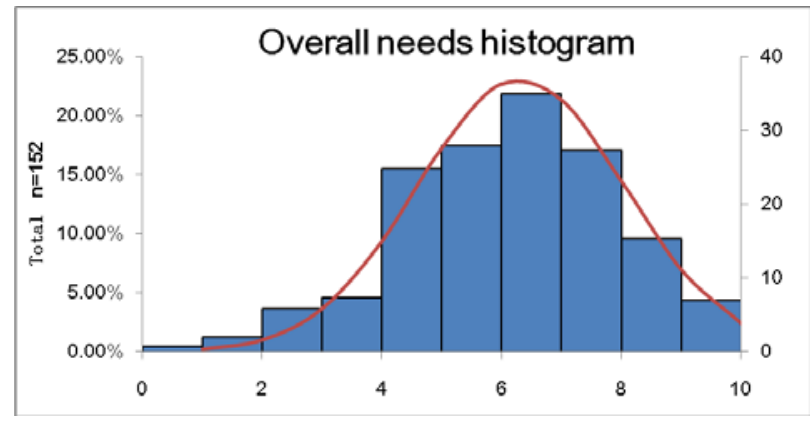

Fig. 1 Results of the green-hand automotive employees in the needs for organizational culture

Separating males and females, it shows high that the degree of the green-hand automotive employees' needs for organizational culture $\left(\mathrm{X}_{1}=6.29, \mathrm{X}_{2}=6.38\right)$, the variances are $\mathrm{S}_{1}=2.93, \mathrm{~S}_{2}=3.29$, and the data distributions of each gender are both closed to the normal distribution (subscript 1 for males, 2 for females, the same below). This shows that the needs for organizational culture of green-hand automotive employees of different genders have high degree of need. (Table 1)

Table 1 Questionnaire results

\begin{tabular}{|c|c|c|c|}
\hline \multirow{2}{*}{ Dimensions } & All $(\mathrm{n}=152)$ & Males $(\mathrm{n} 1=107)$ & Females (n2=45) \\
\cline { 2 - 4 } & $\overline{\mathrm{X} \pm \mathrm{S}}$ & $\overline{\mathrm{X}_{2}} \pm \mathrm{S}_{2}$ & $\overline{\mathrm{X}_{z}} \pm \mathrm{S}_{z}$ \\
\hline F1 & $6.76 \pm 2.55$ & $6.47 \pm 2.27$ & $7.46 \pm 2.57$ \\
\hline F2 & $4.73 \pm 3.05$ & $4.83 \pm 3.52$ & $4.48 \pm 1.87$ \\
\hline F3 & $6.67 \pm 1.63$ & $6.54 \pm 1.56$ & $6.99 \pm 1.69$ \\
\hline F4 & $7.64 \pm 1.91$ & $7.54 \pm 1.98$ & $7.89 \pm 1.69$ \\
\hline F5 & $6.15 \pm 2.31$ & $6.36 \pm 2.34$ & $5.64 \pm 1.91$ \\
\hline F6 & $5.96 \pm 1.84$ & $6.00 \pm 1.81$ & $5.85 \pm 1.96$ \\
\hline
\end{tabular}

“"̄" for need average, "s" for the need variance

Data distributions of needs in overall and of different genders are normal distribution, so that the Z-test method can be used in further research. Needs of the green-hand automotive employees of different genders in each dimension of organizational culture are further studied and performed analysis, as follows:

A. The difference of needs for each dimension of organizational culture between green-hand automotive employees of different genders

Using double overall Z-test method shows that for the green-hand automotive employees of different gender in the needs for organizational culture, F1(authorization) and F5 (cooperation) dimensions are the two significantly higher than other dimensions, that means the they have particularly significant need difference between males and females in the two dimensions. And in the dimensions F2(team orientation), F4 (core value) and F6(coordination and integration), there is 
no significant need difference between males and females. (Shown in Table 2)

B. The difference of needs for each dimension of organizational culture within green-hand automotive employees of the same gender

Using single overall Z-test method shows that the greenhand automotive employees of same gender in the needs for organizational culture. Female employees' Z-test scores in the dimensions F1(authorization) and F5(cooperation) are significantly higher than those in other dimensions. So need difference between females is significant in those dimensions, and in other dimensions is not significant. And male employees have no significant need difference in each dimension, and the Z-test scores in the dimensions F1(authorization) and F5(cooperation) are slightly higher than those in other dimensions by comparison. So need difference between males is slightly significant in those dimensions. However, there is no significant difference in the other dimensions. (Shown in Table 2)

Table 2 Z-test results

\begin{tabular}{|c|c|c|c|}
\hline Dimensions & Different gender & Female & Male \\
\hline F1 & $4.44^{* *}$ & $3.26^{* *}$ & 1.85 \\
\hline F2 & 1.60 & 1.22 & 0.59 \\
\hline F3 & $2.23^{*}$ & 1.66 & 0.92 \\
\hline F4 & 1.71 & 1.28 & 0.67 \\
\hline F5 & $3.39^{* *}$ & $2.53^{*}$ & 1.35 \\
\hline F6 & 0.72 & 0.55 & 0.27 \\
\hline
\end{tabular}

e.g.: $4.44^{* *}, 4.44$ indicates the coefficient of correlation, $* *$ indicates the $\mathrm{P}$ value is less than 0.01 , as the difference is extremely significant, * indicates $\mathrm{P}$ value in the $0.01-0.05$, as the difference is significant; no * indicates that the $P$ value is larger than 0.05 , as the difference is not significant

\section{Conclusion analysis and discussion}

A. Based on the gender perspective, the difference of needs for organizational culture of green-hand automotive employees

By gathering the Z-test scores from Table 1\&2, Figure 2 shows that, the broken line of Z-test scores of different gender employees is higher than the one of the same gender employees in each dimension of organizational culture. That means, on the whole, the difference of needs for organizational culture between green-hand employees of different genders is more significant than the one within the same gender.

Moreover, Figure 2 also shows that, the broken line of Ztest scores of female employees is higher than the one of male employees in each dimension of organizational culture. That means, on the whole, the individual difference of needs for organizational culture within females green-hand employees is more significant than the one within males.

Therefore, our empirical research has not only verified the fundamental hypothesis $\mathrm{H}$, which is based on pre-qualitative research, but also improved H0, so that we get the improved fundamental conclusion HO': The green-hand automotive employees have different needs for organizational culture; based on gender perspective, the difference between different genders is more significant than the one within the same gender, and the individual difference within females is more significant than the one within males.

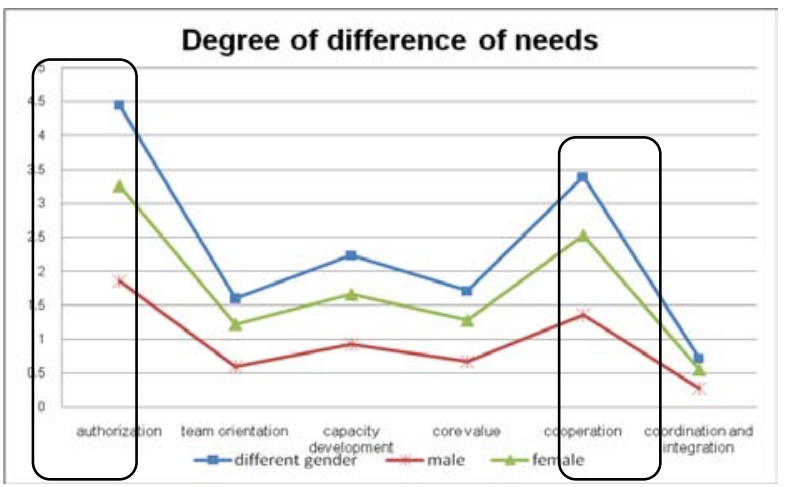

Figure.2 The broken line chart to show gender-based degree of difference of green-hand automotive employees' needs for organizational culture

B. the difference of needs for each dimension of organizational culture between green-hand automotive employees of different genders

Figure 2 shows that, between green-hand automotive employees of different genders, the degrees of difference of their needs for 'authorization' and 'cooperation' are distinctively higher than the other dimensions of organizational culture. Compared with sub-hypothesis H10, this paper has just verified the significant gender difference in 'cooperation', and also proposed the distinction of gender difference in 'authorization'.

The pre-qualitative and this research both show that, compared with female employees, male employees, in the beginning period of working, pursue individual independence more, and not rely on the family. However, after the men build their own family, their needs for family support will be stronger and stronger, so that the distinction of needs' difference between female employees in 'authorization' will be weakened. On the other hand, when female employees are on the initial stage of entering the automotive industry, a malesdominated industry, they will inevitably concerns about future promotion by gender prejudice. However, with the career development, the woman will understand more about the promotion system in her automotive enterprises, so that the distinction of needs' difference between male employees in 'authorization' will be weakened. Therefore, as the sample of pre-qualitative research is the employee who has some working experience, while the one of this research is the new employee, the gender difference in 'authorization' is more significant than the pre-research.

To sum up, the highly significant gender difference in 'authorization' of green-hand automotive employees through our empirical research is not only very rational, but also corrects and improves the sub-hypothesis H10, so that we get the corrected sub-conclusion H10': For the difference of needs for each dimension of organizational culture between greenhand automotive employees of different genders, the gender 
difference is most significant in 'authorization' and 'cooperation'.

C. The difference of needs for each dimension of organizational culture within green-hand automotive employees of the same gender

Figure 2 shows that, within green-hand automotive employees of the same gender, the degrees of difference of their needs for 'authorization' and 'cooperation' are distinctively higher than the other dimensions of organizational culture. This result has not only verified subhypothesis H20, but also proposed the distinction of males' individual difference in 'authorization'.

For this male individual difference, different men will inevitably have different understandings of family because of their environment, character and other factors, especially in the beginning period of working. However, after the men build their own family, their needs for family support will be stronger and stronger, so that the distinction of needs' difference will not only be weakened between female employees in 'authorization', but also within males' individuals. Therefore, the male individual difference in 'authorization' is more significant than the pre-research.

To sum up, the highly significant individual difference in 'authorization' of new males automotive employees through our empirical research is not only very rational, but also improves the sub-hypothesis H20, so that we get the improved sub-conclusion H20': For the difference of needs for each dimension of organizational culture within green-hand automotive employees of the same gender, both males and females have the most significant individual difference in 'authorization' and 'cooperation'.

\section{Conclusion summary and management recommendations}

\section{A. Conclusion summary}

The empirical research based on the previous qualitative research has verification, correction and improvement on the basis of the underlying hypothesis, as the following conclusions:

Fundamental conclusion HO ': The green-hand automotive employees have different needs for organizational culture; based on gender perspective, the difference between different genders is more significant than the one within the same gender, and the individual difference within females is more significant than the one within males

Sub-conclusion H10 ': For the difference of needs for each dimension of organizational culture between green-hand automotive employees of different genders, the gender difference is most significant in 'authorization' and 'cooperation'.

Sub-conclusion H20 ': For the difference of needs for each dimension of organizational culture within green-hand automotive employees of the same gender, both males and females have the most significant individual difference in 'authorization' and 'cooperation'.

\section{B. Management recommendations}

In light of these conclusions, the following management recommendations are proposed:

I. In the process of organizational culture's impact, the difference between the employee genders should be more concerned about.

II. To meet the needs of staff for organizational culture, in addition to give more support to employees on the system, eliminating staff promotion of gender bias (authorization), the auto companies should also focus on leadership training, so that through leadership organizational culture has a more positive impact on employees (cooperation).

\section{Deficiencies and prospects}

There are some limitations in this study. For example, the study selects a university graduates to have an empirical research, due to the gender disproportionate, that women contributes a small sample size, and thus there is some limitations. This paper has not yet in-depth discussion on the differences in some of dimensions, the reason these differences occur, or whether these differences expand or develop into the convergence throughout career development. These questions need to be further studied.

\section{References}

[1] Denison, Daniel R. Corporate culture and organizational effectiveness, Wiley, 1990

[2] Edgar H, Schein. Organizational Culture. American Psychologist, Feb. 1990: 109-119

[3] Hofstede, Geert. Measuring Organizational Culture: A Qualitative Study Across Twenty Cases. Adaministrative Science Quarterly, 1990(35): 285316

[4] Cindy Gordon, Cashing in on corporate culture, CA magazine, JanuaryFebruary 2008

[5] Ren Chong. Act according to actual circumstances-The corporate culture assessment system (CCMS) based on the corporate culture diagnosis model. The Chinese and foreign enterprise culture. 2009(5): 68-72

[6] Edward Gross, "Plus a Change: The Sexual Structure of Occupations over Time”, Social Problems 16: 198-208, 1968.

[7] Li Chunling. The present situation and trend of Chinese occupation gender segregation . Jiangsu Social Sciences, 2009-05

[8] He Li, Ling Wenquan. An Empirical Study on Leadership Style and Job Engagement: Effects on Organizational Culture and Identification. Journal of Strategy and Decision-Making. 2012-09, 3(5): 78-83

[9] Li Xianmiao, Luo Jinlian, Huo Weiwei. A Cross-Temporal Meta-Analysis of the Relationship between Gender Characteristics and Leadership Style. Science of Science and Management of S.\& T., 2012, 33(55): 160-168

[10] Zhang Yan, Wang Hui, Fan Jingli. Effect of organizational support on resource management practices and employees 'performance. Journal of Management Sciences in China, 2008-4, 11(2): 120-131

[11] Li Min, Deng Rong. An Empirical Analysis of the Relationship between Human Resource Management and Employees' Well-being in the Automobile Joint Venture. Soft Science. 2010-04, 24(4): 104-108

[12] Yu Yanping, Luo Jinlian, ZHOU Yanqiu. Work-Family Balance among Females Staff of High-Star Hotels. Collection of Women' s Studies, 2012, (06)

[13] Zhang Yu. Empirical study on gender differences in career self-efficacy of High Vocational Students . Study on the occupation education, 200701: 86-88

[14] Zhong Zhenshan, Mei Yi. The empirical research on College Students' occupation self-efficacy of family factors. Vocational \&Technical Education Forum, 2010(22): 37-40 